06,13

\title{
Изменение элементного состава тонких пленок цирконата-титаната свинца в процессе ионно-плазменного осаждения: эксперимент и моделирование
}

\author{
(C) В.А. Вольпяс ${ }^{1}$, А.Б. Козырев ${ }^{1}$, А.В. Тумаркин ${ }^{1}$, Д.М. Долгинцев ${ }^{2}$, В.П. Пронин ${ }^{2}$, \\ Е.Ю. Каптелов ${ }^{3}$, С.В. Сенкевич ${ }^{3}$, И.П. Пронин ${ }^{3}$ \\ ${ }^{1}$ Государственный электротехнический университет „ЛЭТИ“, \\ Санкт-Петербург, Россия \\ ${ }^{2}$ Российский государственный педагогический университет им. А.И. Герцена, \\ Санкт-Петербург, Россия \\ ${ }^{3}$ Физико-технический институт им. А.Ф. Иофрфе, \\ Санкт-Петербург, Россия \\ ๑ E-mail: Petrovich@mail.ioffe.ru
}

Поступила в Редакцию 21 февраля 2019 г.

В окончательной редакции 21 февраля 2019 г.

Принята к публикации 26 февраля 2019 г.

Экспериментально исследовано изменение элементного состава тонких пленок РZT, полученных методом ВЧ магнетронного распыления при вариации давления рабочего газа. Интерпретация полученных экспериментальных результатов проведена на основе статистического моделирования процессов термализации и диффузии потоков распыленных атомов $\mathrm{Pb}, \mathrm{Zr}$ и Тi при ионно-плазменном осаждении тонких пленок PZT. Показано, что результаты моделирования достаточно корректно (в пределах 5\%) описывают изменение элементного состава при различных значениях давления газовой среды. Проведенные исследования позволяют получать тонкие пленки РZT с заданным элементным составом, что важно для оптимизации электрофизических свойств твердых растворов, относящихся к области морфотропной фазовой границы.

Ключевые слова: сегнетоэлектрики, тонкие пленки РZT, элементный состав, моделирование ионно-плазменных процессов.

DOI: 10.21883/FTT.2019.07.47838.388

\section{1. Введение}

Тонкие сегнетоэлектрические пленки цирконата-титаната свинца $\left(\mathrm{PbZr}_{1-x} \mathrm{Ti}_{x} \mathrm{O}_{3}\right.$ или $\left.\mathrm{PZT}\right)$ являются базовыми материалами для устройств микроэлектромеханики $[1,2]$. Экстремальные диэлектрические и электромеханические свойства твердых растворов PZT, как хорошо известно [3], наблюдаются в узкой области концентраций, соответствующей морфотропной фазовой границе (МФГ) (при $x \sim 0.46-0.48)$, которая разделяет тетрагональную и ромбоэдрическую модификации сегнетоэлектрической фазы. В работах $[4,5]$ предполагается, что такие свойства определяются промежуточной моноклинной фазой в области МФГ, стабильность которой зависит от гомогенности состава, микроструктуры и механических напряжений. Поиск композиций с оптимальными электромеханическими параметрами, в значительной степени, связан с тонким варьированием состава (элементного соотношения атомов $\mathrm{Zr}$ и $\mathrm{Ti}$ ) в пределах области МФГ.

Наибольший практический интерес представляют так называемые самополяризованные пленки, в которых макроскопическая поляризация возникает в процессе их формирования [6-9]. Такие пленки не только не нуждаются в дополнительной поляризационной процедуре, но и оказываются более устойчивыми к воздействию внешнего электрического поля. Согласно [6-8] причиной возникновения самополяризации является поляризующее действие объемного заряда, локализованного вблизи нижнего интерфейса сегнетоэлектрического слоя. В частности, в [8] показано, что величина самополяризации зависит от избыточного содержания свинца, присутствующего в пленках в виде оксида, приводящего к образованию отрицательного объемного заряда.

Одним из возможных способов варьирования состава многокомпонентных тонких пленок является управление технологическими параметрами в процессе ионноплазменного осаждения пленок. Разработанный в [10,11] подход был успешно использован в [12] при магнетронном осаждении тонких слоев титаната бария-стронция $\mathrm{Ba}_{x} \mathrm{Sr}_{1-x} \mathrm{TiO}_{3}$ (BST) в кислородной плазме. При этом было получено хорошее количественное согласие экспериментальных данных с результатами статистического моделирования по стехиометрическому составу тонких слоев титаната бария-стронция, полученных ВЧ магнетронным распылением керамической мишени $\mathrm{Ba}_{0.3} \mathrm{Ti}_{0.7} \mathrm{O}_{3}$, при вариации давления рабочего газа. Было показано, что для мишени с исходной стехиометрией $\mathrm{Ba}_{0.3} \mathrm{Sr}_{0.7} \mathrm{TiO}_{3}$, изменение давления кислорода от 2 до 60 Ра приводило к варьированию стехиометрического 
состава осажденных пленок в диапазоне $x=0.15-0.30$ за счет создания в пространстве дрейфа мишень-подложка направленных потоков одних компонентов на подложку и диффузионных потоков других.

Описанный выше способ управления технологическими параметрами в части изменения давления рабочего газа при фиксировании расстоянии от подложки до мишени был применен в настоящей работе для моделирования процессов термализации и диффузии в ионно-плазменной среде при распылении керамической мишени PZT и сравнения полученных результатов с экспериментальными данными.

\section{2. Приготовление образцов и методы исследования}

Осаждение тонких слоев PZT осуществлялось в установке высокочастотного (ВЧ) магнетронного распыления керамической мишени. Геометрия использованной распылительной системы схематично представлена на рис. 1. Состав распыляемой керамической мишени РZT соответствовал атомному соотношению $\mathrm{Zr} / \mathrm{Ti} \sim 0.54 / 0.46$, входящему в область МФГ. В мишень добавлялся избыток свинца (в виде $10 \mathrm{~mol} \% \mathrm{PbO}$ ), необходимый для компенсации потерь свинца в процессе высокотемпературного отжига. В качестве рабочего газа использовалась аргонокислородная смесь $\left(80 \% \mathrm{O}_{2}+20 \% \mathrm{Ar}\right)$. Осаждение слоев РZT проводилось на платинированные кремниевые подложки $\mathrm{Pt} / \mathrm{TiO}_{2} / \mathrm{SiO}_{2} / \mathrm{Si}$ при низкой температуре $\left(T_{\text {sub }} \sim 150^{\circ} \mathrm{C}\right)$ и давлениях рабочего газа в диапазоне от 2 до $8 \mathrm{~Pa}$ при расстоянии от мишени до подложки, равном $50 \mathrm{~mm}$. Толщина осажденных слоев составляла $\sim 800 \mathrm{~nm}$. Для формирования фазы перовскита, пленки затем отжигались на воздухе при $T_{\text {ann }} \sim 600^{\circ} \mathrm{C}$.

Для исследования микроструктуры и состава пленок использовался растровый электронный микроскоп EVO-40, Carl Zeiss, оснащенный энергодисперсионной приставкой INCA. Фазовый контроль осуществлялся с помощью рентгенодифракционного метода $\theta-2 \theta$

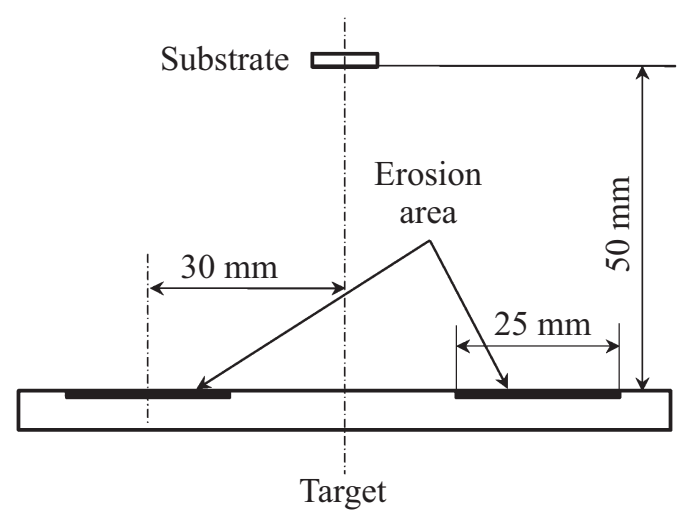

Рис. 1. Геометрия распылительной системы ВЧ магнетронного осаждения.
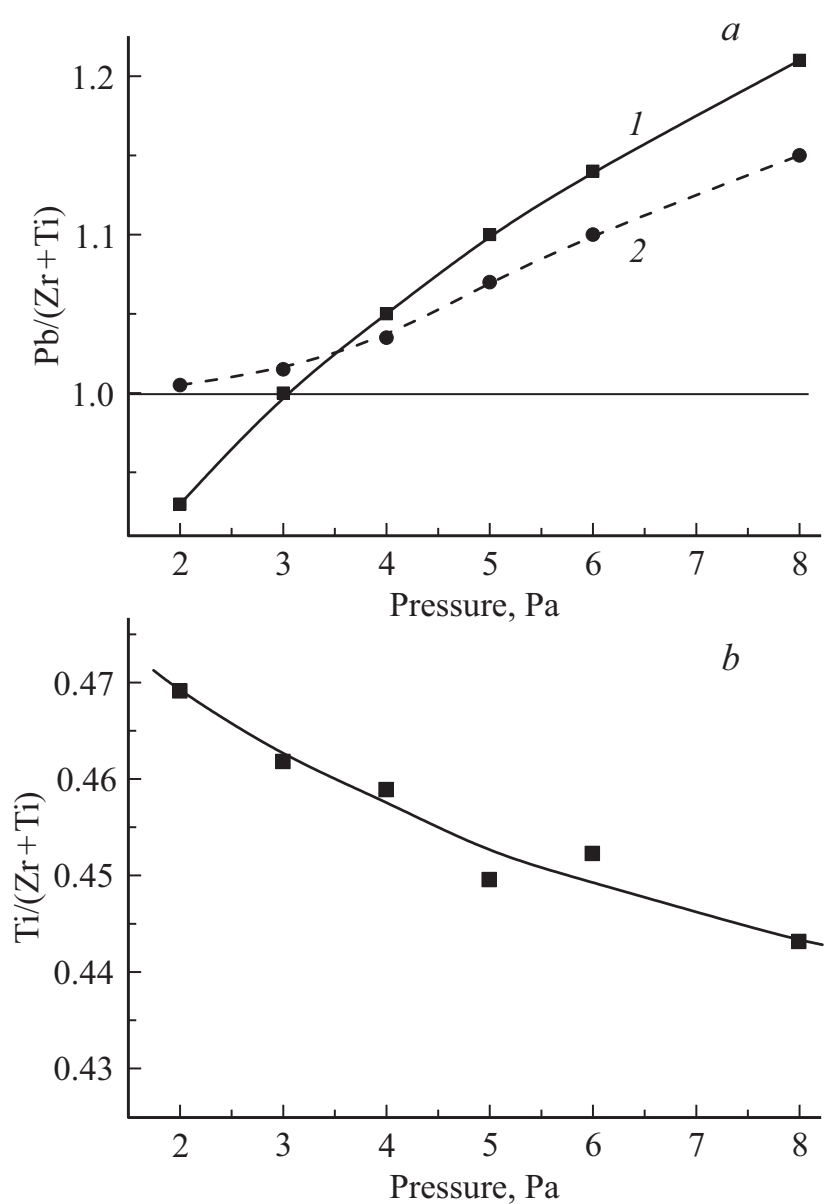

Рис. 2. Изменение элементного соотношения $\mathrm{Pb} /(\mathrm{Zr}+\mathrm{Ti})(a)$ и $\mathrm{Ti} /(\mathrm{Ti}+\mathrm{Zr})$ (b) при вариации давления рабочей газовой смеси в PZT тонких слоях. Кривая 1 на рис. $2, a$ соответствует содержанию свинца в осажденных пленках, кривая 2 отражает содержание свинца в отожженных пленках, измеренного в фазе перовскита.

(ДРОН-7) и оптической микроскопии (Nikon Eclipse LV150).

\section{3. Экспериментальные результаты и моделирование процессов термализации}

Полученные данные по составу осажденных (аморфных) пленок показали, что элементное содержание атомов свинца, представленное в относительных единицах $\mathrm{Pb} /(\mathrm{Zr}+\mathrm{Ti})$, монотонно возрастало с увеличением давления рабочего газа в диапазоне 2-8 Ра (кривая 1 на рис. 2,a). При 2 Ра фиксировался недостаток свинца в 7\% относительно стехиометрического состава PZT $(\mathrm{Pb} /(\mathrm{Zr}+\mathrm{Ti}) \sim 0.93)$, а при $8 \mathrm{~Pa}$ наблюдался значительный избыток атомов свинца величиной в $21 \%$ $(\mathrm{Pb} /(\mathrm{Zr}+\mathrm{Ti}) \sim 1.21)$. Изменения в соотношении атомов, занимающих октаэдрические позиции в перовскитовой решетке ( $\mathrm{Ti}$ и $\mathrm{Zr}$ ), оказывались не столь сильными. 
Зависимость элементного соотношения $\mathrm{Ti} /(\mathrm{Zr}+\mathrm{Ti})$ с ростом давления носила также монотонный характер (рис. $2, b$ ). В целом, диапазон их изменения составлял $\sim 2.5 \%$, охватывая большую часть области МФГ.

Высокотемпературный отжиг пленок показал, что при высоком давлении рабочего газа (6-8 Pa) кристаллизация фазы перовскита (Ре) происходит практически во всем объеме пленки. При дальнейшем снижении давления содержание фазы перовскита падало (рис. 3 и рис. $4, a, b)$, и при низком давлении (3 Pa) фаза перовскита представляла собой отдельные перовскитовые островки, расположенные в матрице низкотемпературной фазы пирохлора (Ру) (рис. 4,b). Причины такого снижения связаны с уменьшением содержания свинца в пленке за счет высокой волатильности паров оксида свинца. При высоком давлении рабочего газа (при $8 \mathrm{~Pa}$ ) его падение составляло $\sim 7 \%$, а при низком давлении в перовскитовых островках его содержание не снижалось ниже стехиометрического, что было связано с перераспределением свинца между фазами перовскита и пирохлора (кривая 2 на рис. 2, a) [13]. Высокотемпературный отжиг не приводил, в пределах погрешности измерений, к какому-либо заметному изменению в соотношении атомов $\mathrm{Zr}$ и Ti.

Рассмотрим физическую интерпретацию полученных экспериментальных результатов, представленных выше, на основе статистического моделирования процессов термализации и диффузии потоков распыленных атомов $\mathrm{Pb}, \mathrm{Zr}$ и Ti при ионно-плазменном осаждении тонких пленок PZT.

Потоки распыленных атомов характеризуются соответствующими пространственными, энергетическими и угловыми распределениями, обусловленные энергетическими характеристиками и свойствами ионов и атомов рабочего газа $\left(\mathrm{Ar}+\mathrm{O}_{2}\right)$, бомбардирующих катодмишень, и свойствами самой мишени $[14,15]$.

Анализ процессов рассеяния при столкновении атомных частиц в пространстве дрейфа мишень-подложка показывает, что переход распыленных атомов из направленного потока с энергией $E \gg k T$ в диффузионный режим движения с энергией $E \sim k T$ можно характеризовать их пространственной зоной термализации. Под термализацией атомных частиц следует понимать потерю ими энергии при последовательных столкновениях с частицами газовой среды до состояния термодинамического равновесия с ней [11]. Величина диффузионных потоков распыленных атомов определяется градиентом плотности потока термализованных распыленных атомов, граница термализации которых существенным образом зависит как от соотношения масс атомов распыляемой мишени и атомов рабочего газа, так и от спектра начальных энергий распыленных атомов, определяемого их энергией связи в мишени и энергией бомбардирующих мишень ионов. Движение распыленных атомов в пределах пространственной зоны их термализации носит преимущественно направленный характер от мишени к подложке, вне зоны термализации распыленные атомы переходят в диффузионный режим движения, и их распространение носит в дальнейшем изотропный характер. В результате термализации первоначального потока распыленных атомов изменяется как сама форма и размеры пространственной зоны термализации, так и соотношение прямого и диффузионного потоков в ней.

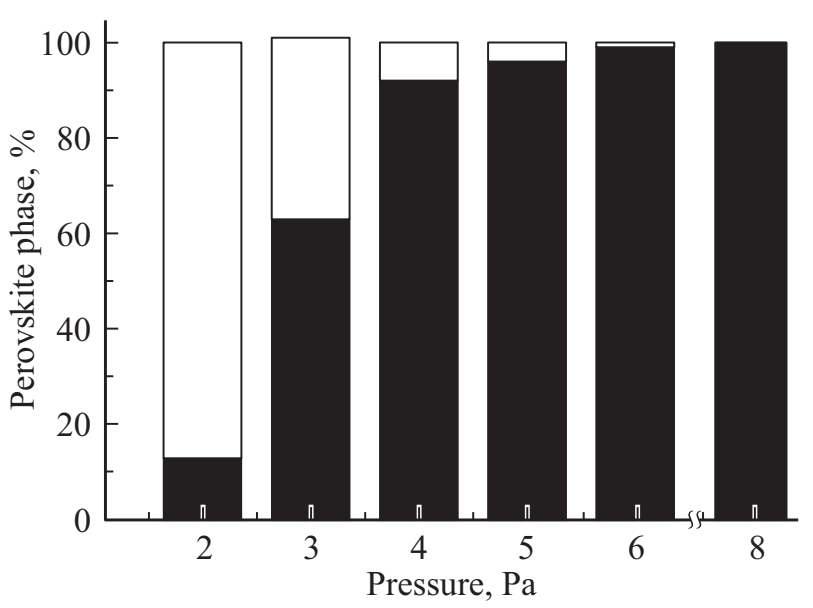

Рис. 3. Гистограмма, отражающая содержания фазы перовскита в тонких пленках PZT осажденных при вариации давления рабочего газа и отожженных на воздухе при $600^{\circ} \mathrm{C}$.
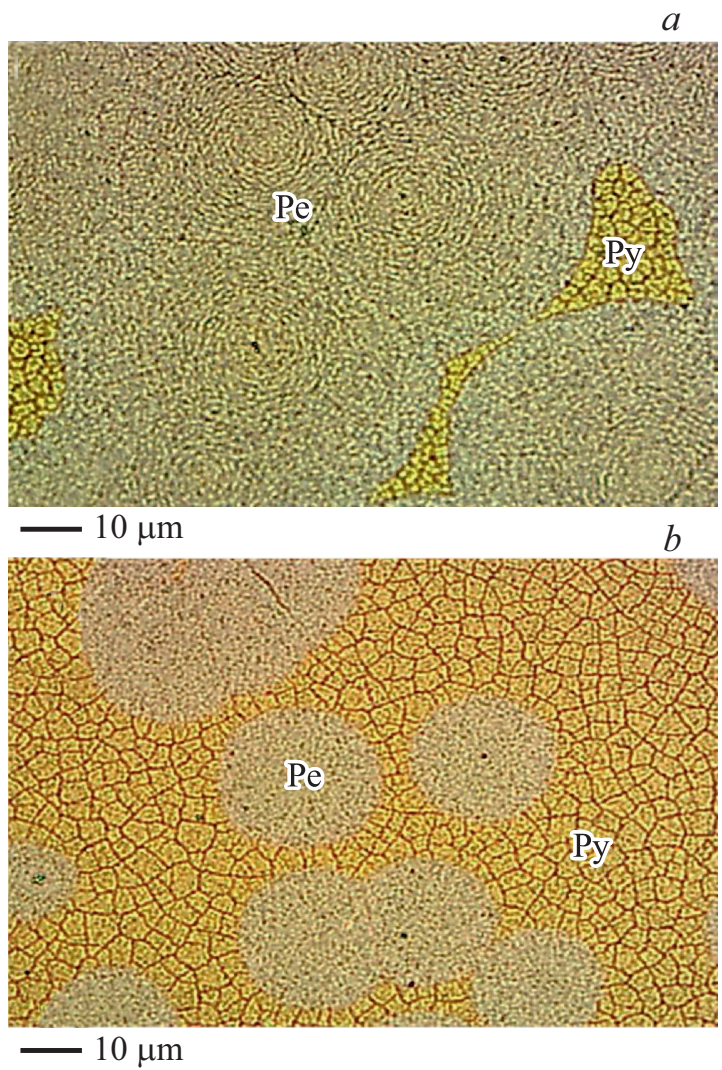

Рис. 4. Оптическое изображение фазового контраста фаз пирохлора (Ру) и перовскита (Ре) тонких пленок РZT, осажденных при давлениях $5 \mathrm{~Pa}(a)$ и $3 \mathrm{~Pa}(b)$ рабочего газа и отожженных на воздухе при $600^{\circ} \mathrm{C}$. 


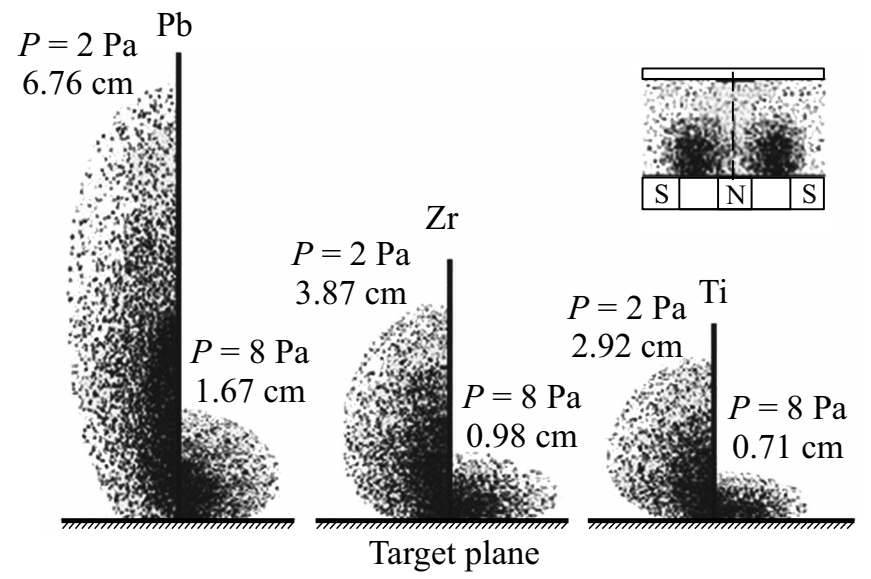

Рис. 5. Зоны термализации потоков распыленных атомов $\mathrm{Pb}, \mathrm{Zr}$ и $\mathrm{Ti}$ в пространстве дрейфа мишень-подложка при различных давлениях рабочего газа $\mathrm{Ar}+\mathrm{O}_{2}$.

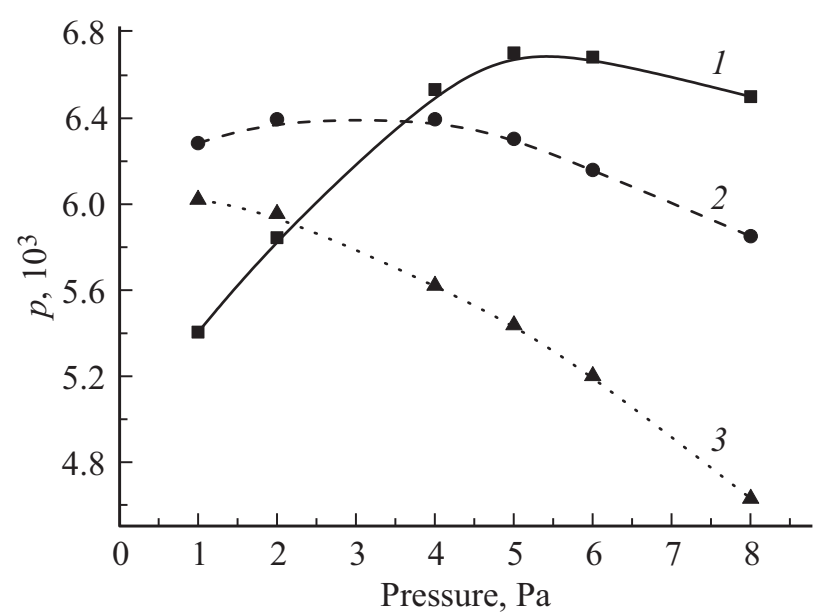

Рис. 6. Вероятности доставки распыленных атомов $\mathrm{Pb}$ (кривая 1), $\mathrm{Zr}$ (кривая 2) и $\mathrm{Ti}$ (кривая 3) при различных давлениях рабочего газа $\mathrm{Ar}+\mathrm{O}_{2}$.

В соответствии с алгоритмом, подробно описанным в [11], характерный вид рассчитанной пространственной зоны термализации потоков распыленных атомов свинца $\mathrm{Pb}, \mathrm{Zr}$ и $\mathrm{Ti}$ при различных давлениях рабочего газа $\left(\mathrm{Ar}+\mathrm{O}_{2}\right)$ представлен на рис. 5. Величина представленной границы пространственной зоны термализации распыленных атомов соответствует термализации 95\% их первоначального потока.

Рабочий диапазон давлений газовой среды в процессе ВЧ магнетронного ионно-плазменного распыления многокомпонентных оксидных керамических мишеней составляет 1-20 Ра, что соответствует скоростям осаждения многокомпонентных оксидных пленок примерно $5-1 \mathrm{~nm} / \mathrm{min}$. Согласно результатам статистического моделирования (рис. 5), при величине давления рабочего газа 2 Ра глубина зоны термализации атомов $\mathrm{Pb}(\sim 6.7 \mathrm{~cm})$ превышает расстояние мишеньподложка $(5 \mathrm{~cm})$ и, следовательно, на подложку они осаждаются как из прямого потока, так и в диффузионном режиме. Глубина же зоны термализации атомов $\mathrm{Zr}$ $(\sim 3.8 \mathrm{~cm})$ и $\mathrm{Ti}(\sim 2.9 \mathrm{~cm})$ меньше расстояния дрейфа мишень-подложка и поэтому на подложку они осаждаются преимущественно в диффузионном режиме. При увеличении давления рабочего газа глубина пространственной зоны термализации всех распыленных атомов из мишени PZT становится меньше расстояния дрейфа мишень-подложка, и на подложку они осаждаются в диффузионном режиме.

Для интерпретации полученных экспериментальных результатов, представленных на рис. 2, на основе разработанной модели процесса осаждения тонких многокомпонентных пленок при ионно-плазменном распылении аморфных и поликристаллических материалов [16] были определены вероятности доставки из активной зоны распыления мишени на подложку каждой из компонент распыляемой мишени PZT. Соответствующие вероятности доставки распыленных атомов $\mathrm{Pb}, \mathrm{Zr}$ и Тi при различных значениях давления $\mathrm{Ar}+\mathrm{O}_{2}$ газовой среды представлены на рис. 6.

Сравнительный анализ распределения вероятности доставки распыленных атомов $\mathrm{Pb}, \mathrm{Zr}$ и Ті при различных значениях давления газовой среды показывает, что подложка, расположенная на оси распылительной системы, при низких давлениях $(P<3 \mathrm{~Pa})$ оказывается обедненной свинцом и обогащенной цирконием и титаном.

При увеличении давления рабочего газа до $8 \mathrm{~Pa}$ длина зоны термализации атомов $\mathrm{Pb}, \mathrm{Zr}$ и $\mathrm{Ti}$ сокращается (рис. 5) и становится существенно меньше, чем расстояние мишень-подложка. В силу разницы в массах „виртуальный“ источник диффузионных атомов $\mathrm{Pb}$ находится ближе к подложке, чем у атомов $\mathrm{Zr}$ и Ti. Поэтому плотность потока осаждаемых на подложку атомов $\mathrm{Pb}$ будет больше, чем у осаждаемых атомов Zr и Ti, и элементное соотношение $\mathrm{Pb} /(\mathrm{Zr}+\mathrm{Ti})$ в пленке будет увеличиваться. При этом скорость осаждения распыленных атомов на подложку может существенно уменьшаться в области высоких давлений.

Сравнение результатов эксперимента по изменению элементного состава $\mathrm{Pb} /(\mathrm{Zr}+\mathrm{Ti})$ пленки при изменении давления рабочего газа (рост пленки на подложке) и соответствующих результатов статистического моделирования (доставка распыленных атомов мишени на подложку) имеет вид, представленный на рис. 7. Видно, что экспериментальная и рассчитанная кривые качественно ведут себя одинаково, и расхождение между ними не превышает 2-3\%. При увеличении давления рабочего газа состав потоков распыленных атомов $\mathrm{Pb}, \mathrm{Zr}$ и $\mathrm{Ti}$, достигших поверхности подложки, расположенной в центре магнетронной распылительной системы, изменяется в сторону увеличения поверхностной плотности атомов $\mathrm{Pb}$. Это обусловлено тем, что длина зоны термализации для распыленных атомов $\mathrm{Zr}$ и Ті при увеличении давления рабочего газа уменьшается значительнее быстрее, чем для более тяжелой компоненты потока распыленных атомов $\mathrm{Pb}$. Поэтому эффекты рассеяния в 

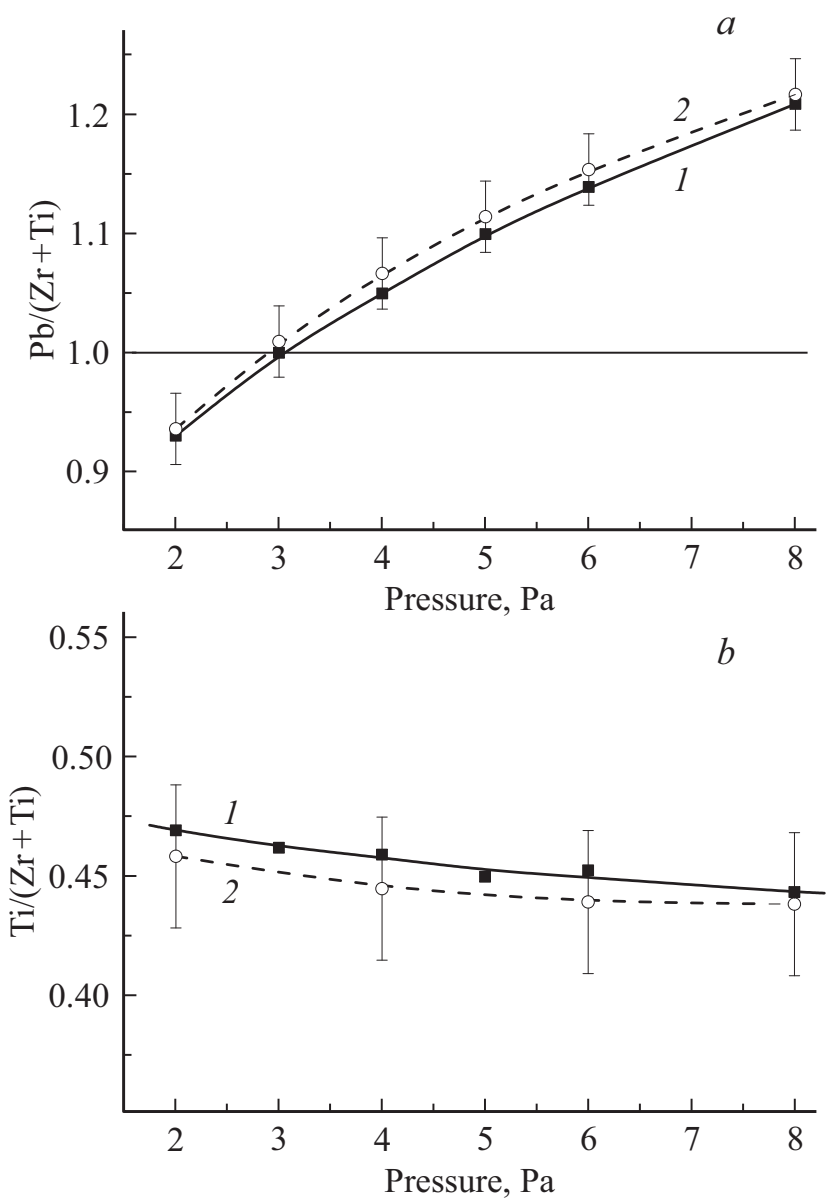

Рис. 7. Сравнение результатов эксперимента (кривая 1) и статистического моделирования (кривая 2) по содержанию $\mathrm{Pb} /(\mathrm{Zr}+\mathrm{Ti})(a)$ и $\mathrm{Ti} /(\mathrm{Ti}+\mathrm{Zr})(b)$ в $\mathrm{PZT}$ пленке.

пространстве дрейфа мишень-подложка для атомов $\mathrm{Zr}$ и тем более атомов $\mathrm{Ti}$, по сравнению с атомами $\mathrm{Pb}$, будут выражены значительнее сильнее.

Сравнение экспериментальной и расчетной зависимостей атомного соотношения распыленных атомов циркония и титана $(\mathrm{Zr} / \mathrm{Ti})$ показывает, что их поведение хорошо коррелирует во всем диапазоне изменения давления рабочего газа (рис. 7). Небольшое падение содержания атомов титана вызвано более быстрым уменьшением длины термализации, чем у атомов циркония и не превышало $\sim 2.5 \%$ в исследованном интервале изменения давления.

\section{4. Выводы}

Таким образом, в работе показано, что при использовании одной мишени варьированием рабочей газовой смеси $\mathrm{Ar}+\mathrm{O}_{2}$ в диапазоне 2-8 Ра можно синтезировать тонкие пленки PZT различного состава в пределах морфотропной фазовой границы, а также в широких пределах изменять содержание атомов свинца. Последнее важно для исследования и оптимизации униполярного состояния. Выявлен диапазон давлений рабочего газа, при котором не удается сформировать однофазную перовскитовую структуру PZT слоя.

Сравнение экспериментальных результатов и результатов статистического моделирования показали адекватность используемых подходов для описания процессов ионно-плазменного распыления пленок PZT. Это позволяет расчетным путем выбирать режимы технологического процесса для получения пленок PZT заданного состава.

\section{Конфликт интересов}

Авторы заявляют, что у них нет конфликта интересов.

\section{Список литературы}

[1] S. Trolier-McKinstry, P. Muralt. J. Electroceram. 12, 7 (2004).

[2] P. Muralt. J. Am. Cer. Soc. 91, 1385 (2008).

[3] Б. Яффе, У. Кук, Г. Яффе. Пьезоэлектрическая керамика. Мир, М. (1974) 288 c.

[4] B. Noheda, D.E. Cox, G. Shirane, J.A. Gonzalo, L.E. Cross, S.-E. Park. Appl. Phys. Lett. 74, 2059 (1999).

[5] B. Noheda, D.E. Cox. Phase Transitions 79, 5 (2006).

[6] A.L. Kholkin, K.G. Brooks, D.V. Taylor, S. Hiboux, N. Setter. Integrated Ferroelectrics 22, 525 (1998).

[7] И.П. Пронин, Е.Ю. Каптелов, Е.А. Тараканов, В.П. Афанасьев. ФТТ 44, 1659 (2002).

[8] В.В. Осипов, Д.А. Киселев, Е.Ю. Каптелов, С.В. Сенкевич, И.П. Пронин. ФТТ 57, 1748 (2015).

[9] J.-S. Yang, Y.S. Kang, I. Kang, S.M. Lim, S.J. Shin, J.W. Lee, K. Nur. IEEE Trans. Ultrason., Ferroelectr. Frequency Control 64, 3, 617 (2017).

[10] В.А. Вольпяс, А.Б. Козырев. ЖЭТФ 140, 1, 196 (2011).

[11] V.A. Volpyas, A.Y. Komlev, R.A. Platonov, A.B. Kozyrev. Phys. Lett. A 378, 3182 (2014).

[12] В.А. Вольпяс, А.В. Тумаркин, А.К. Михайлов, А.Б. Козырев, Р.А. Платонов. Письма в ЖТФ 42, 14, 87 (2016).

[13] Д.М. Долгинцев, В.П. Пронин Е.Ю. Каптелов, С.В. Сенкевич, И.П. Пронин. Письма в ЖТФ 45, 6, 3 (2019).

[14] G.M. Turner, I.S. Falconer, B.W. James, D.R.J. McKenzie. Appl. Phys. 65, 3671 (1989).

[15] C.S. Nimisha, G. Mohan Rao. J. Appl. Phys. 109, 114910 (2011).

[16] E.K. Hollmann, V.A. Volpyas, R. Wordenweber. Physica C 425, 101 (2005).

Редактор Ю.Э. Китаев 